\title{
Immobilized pH Gradient Gel Cell To Study the pH Dependence of Drug Lipophilicity
}

\author{
Hoang-Trang Lam, ${ }^{\dagger}$ Carlos M. Pereira, ${ }^{\ddagger}$ Christophe Roussel, ${ }^{\dagger}$ Pierre-Alain Carrupt, $\$$ and \\ Hubert H. Girault*,t \\ Laboratoire d'Electrochimie Physique et Analytique, Ecole Polytechnique Fédérale de Lausanne, Station 6, \\ CH-1015 Lausanne, Switzerland, Departamento de Química, Faculdade de Cièncias da Universidade do Porto, \\ R. Campo Alegre 687, 4169-007 Porto, Portugal, and Unité de Chimie Pharmaceutique, Université de Genève, \\ $\mathrm{CH}-1211$ Geneve, Switzerland
}

An experimental setup to study the $\mathrm{pH}$ dependence of standard ion-transfer potentials at the water/NPOE interface is presented. The system is composed of a microhole generated by laser photoablation in a $12-\mu \mathrm{m}$ polyethylene terephthalate film, the aqueous phase consisting of a commercial immobilized $\mathrm{pH}$ gradient gel reswelled in electrolyte solution and a droplet of organic solution. Two electrodes are used, an $\mathrm{Ag} / \mathrm{AgCl}$ aqueous electrode and an $\mathrm{Ag} / \mathrm{AgTPBCl}$ organic electrode. This setup is applied to the study of two ionizable compounds (pyridine, 2,4-dinitrophenol). Thermodynamic parameters such as the standard transfer potential, the Gibbs energy of transfer, and the partition coefficients of the ionized forms as well as the neutral forms of these drug compounds are evaluated by differential pulse voltammetry. The data obtained are summarized in ionic partition diagrams, which are a useful tool for predicting and interpreting the transfer behavior of ionized drugs at the liquid/liquid interfaces mimicking the biological membranes.

Recently, the electrochemical study of the transfer of ionic species across the interface between two immiscible electrolyte solutions (ITIES) has gained great significance due to its wide applicability in different fields such as ion-selective electrodes for application to amperometric sensors, solvent extraction, drug lipophilicity, and its consequences on drug delivery. ${ }^{1-4}$ Unlike numerous traditional chromatographic and potentiometric systems developed to study the distribution of ionic species and giving an indirect access to partition coefficients, voltammetry at the ITIES allowed us to evaluate the standard partition coefficient of both the neutral and the ionized forms. ${ }^{5,6}$ The four-electrode system initially introduced by Samec et al. ${ }^{7}$ was later used intensively by

\footnotetext{
* To whom the correspondence should be addressed. E-mail: hubert.girault@ epfl.ch. Fax: 0041216933667.

† Ecole Polytechnique Fédérale de Lausanne.

₹ Universidade do Porto.

$\S$ Université de Genève.

(1) Reymond, F.; Fermin, D.; Lee, H. J.; Girault, H. H. Electrochim. Acta 2000, 45, 2647-2662.

(2) Reymond, F.; Chopineaux-Courtois, V.; Steyaert, G.; Bouchard, G.; Carrupt, P. A.; Testa, B.; Girault, H. H. J. Electroanal. Chem. 1999, 462, 235-250.

(3) Qian, Q. S.; Wilson, G. S.; Bowman-James, K.; Girault, H. H. Anal. Chem. 2001, 73, 497-503.

(4) Beni, V.; Ghita, M.; Arrigan, D. W. M. Biosens. Bioelectron. 2005, 20, $2097-$ 2103.
}

10.1021/ac051808a CCC: $\$ 33.50$ (c) 2006 American Chemical Society Published on Web 01/25/2006
Reymond et $\mathrm{al}^{2}{ }^{2}$ to study the transfer of many ionizable drugs at the interface between water and 1,2-dichloroethane (DCE), and the introduction of ionic partition diagrams revealed a most interesting aspect for the study of drug lipophilicity. ${ }^{8}$ Indeed, a partition diagram of a specific drug between two immiscible liquids is a representation of the conditions corresponding to the predominance of different forms of the compound (basic, neutral, acid) as a function of the Galvani potential difference and the $\mathrm{pH}$ of the aqueous phase. This representation has been revealed to be a useful tool to mimic the passage of a drug through a biological membrane and help understand the action of that drug.

However, the initial systems used to study the distribution of ionic species between two immiscible solutions used large ITIES, requiring quite large volumes of each phase ${ }^{2}$. Thus, when only limited amount of species is available, micro-ITIES are more suitable, such as liquid/liquid (L/L) interfaces supported at the tip of micropipets ${ }^{9,10}$ or systems using a droplet of organic phase or aqueous phase. ${ }^{11,12}$ For example, Gobry et al. ${ }^{13}$ reported experiments with an aqueous droplet supported at an $\mathrm{Ag} / \mathrm{AgCl}$ disk electrode covered with an organic solution. More recently, Ulmeanu et al. ${ }^{14}$ have studied the profiling of ionized drugs using a fourelectrode system and small volumes of phase in a 96-well plate, to study transfer reactions at a water/2-nitrophenyl octyl ether (NPOE) interface, allowing us to trace ionic partition diagrams of lipophilic compounds. Zhang et al. ${ }^{15}$ recently reported the study of ionizable drug transfer across the water/DCE interface with a three-electrode system, using limited amount of drugs.

(5) Liu, X.; Bouchard, G.; Girault, H. H.; Testa, B.; Carrupt, P. A. Anal. Chem. 2003, 75, 7036 .

(6) Bouchard, G.; Galland, A.; Carrupt, P. A.; Gulaboski, R.; Mirceski, V.; Scholz, F.; Girault, H. H. Phys. Chem. Chem. Phys. 2003, 5, 3748-3751.

(7) Samec, Z.; Marecek, V.; Koryta, J.; Khalil, M. W.J. Electroanal. Chem. 1977, $83,393-397$.

(8) Reymond, F.; Steyaert, G.; Carrupt, P. A.; Testa, B.; Girault, H. J. Am. Chem. Soc. 1996, 118, 11951-11957.

(9) Stewart, A. A.; Taylor, G.; Girault, H. H.; Mcaleer, J. J. Electroanal. Chem. 1990, 296, 491-515.

(10) Stewart, A. A.; Shao, Y.; Pereira, C. M.; Girault, H. H. J. Electroanal. Chem. 1991, 305, 135-139.

(11) Nakatani, K.; Sudo, M.; Kitamura, N. Anal. Chem. 2000, 72, 339-342.

(12) Ulmeanu, S.; Lee, H. J.; Fermin, D. J.; Girault, H. H.; Shao, Y. H. Electrochem. Commun. 2001, 3, 219-223.

(13) Gobry, V.; Ulmeanu, S.; Reymond, F.; Bouchard, G.; Carrupt, P. A.; Testa, B.; Girault, H. H. J. Am. Chem. Soc. 2001, 123, 10684-10690.

(14) Ulmeanu, S. M.; Jensen, H.; Bouchard, G.; Carrupt, P. A.; Girault, H. H. Pharm. Res. 2003, 20, 1317-1322. 
Until now, many studies on partition coefficients have been achieved at a water/DCE interface and biological interpretations based on cyclic voltammetry measurements have only been made for these systems. ${ }^{8,16,17}$ However, the high volatility and the toxicity of DCE limit its use and call for its replacement by a more appropriate organic solvent. Given its absence of known toxicity and interesting physicochemical properties (low solubility in water, low vapor pressure), NPOE has recently been introduced as an alternative for DCE in electrochemistry ${ }^{18,19}$ and medicinal chemistry. ${ }^{5,20}$ In addition, solvatochromic analysis have shown NPOE to be a good candidate to replace DCE in measurements of lipophilicity. ${ }^{20,21}$ Furthermore, it has been shown that for a series of small ions the Gibbs energy of ion transfer from water to DCE directly correlates with the Gibbs energy of ion transfer from water to NPOE, ${ }^{18,22}$ suggesting that the standard partition coefficient in NPOE offers a convenient alternative to the one in DCE.

In the present paper, we describe a two-electrode setup to study the transfer of ionizable compounds at a microinterface water/ NPOE where a commercial immobilized pH gradient (IPG) gel is originally taken as the aqueous phase, with the aim of tracing the ionic partition diagrams for two lipophilic compounds. IPG gels, offering linear $\mathrm{pH}$ gradients, have long been commercialized with the aim to serve proteomics studies and, more precisely, to be used in fractionation methods, such as isoelectric focusing and 2D gel electrophoresis. ${ }^{23,24}$ Recently, the use of IPG gel was reported for the size-selective separation of gold nanoparticles by IEF. ${ }^{25}$ Besides, the influence of the presence of a gel in the water phase on the transfer of ionic compounds across a large water/ DCE interface was investigated by Fantini et al., ${ }^{26}$ and the experimental characteristics of the drug transfer were shown to be in good agreement with a nongelled water/DCE interface. In addition, it was pointed out that a gel/liquid interface has a better mechanical stability than a liquid/liquid interface. With the use of an IPG gel in the present setup, there is no need to prepare several aqueous solutions at different $\mathrm{pH}$ to scan the overall $\mathrm{pH}$ domain to obtain the ionic partition diagram of a specific drug. Using this method, after few improvements, a high-throughput system to measure the partition diagram of a specific drug in one experiment could be obtained. With the proposed system using a microinterface, the $I R$ drop effect is not too high, when compared

(15) Zhang, M. Q.; Sun, P.; Chen, Y.; Li, F.; Gao, Z.; Shao, Y. H. Anal. Chem. 2003, 75, 4341-4345.

(16) Smith, D. A.; van de Waterbeemd, H. Curr. Opin. Chem. Biol. 1999, 3 , 373-378.

(17) Reymond, F.; Carrupt, P. A.; Testa, B.; Girault, H. H. Chem.- Eur. J. 1999, $5,39-47$.

(18) Wilke, S.; Zerihun, T. J. Electroanal. Chem. 2001, 515, 52-60.

(19) Samec, Z.; Langmaier, J.; Trojanek, A.; Samcova, E.; Malek, J. Anal. Sci. 1998, 14, 35-41.

(20) Liu, X.; Bouchard, G.; Müller, N.; Galland, A.; Girault, H. H.; Testa, B.; Carrupt, P. A. Helv. Chim. Acta 2003, 86, 3533.

(21) Gulaboski, R.; Galland, A.; Bouchard, G.; Caban, K.; Kretschmer, A.; Carrupt, P. A.; Stojek, Z.; Girault, H. H.; Scholz, F. J. Phys. Chem. B 2004, 108, 45654572.

(22) Samec, Z.; Langmaier, J.; Trojanek, A. J. Electroanal. Chem. 1996, 409, $1-7$.

(23) Gorg, A.; Obermaier, C.; Boguth, G.; Harder, A.; Scheibe, B.; Wildgruber, R.; Weiss, W. Electrophoresis 2000, 21, 1037-1053.

(24) Michel, P. E.; Reymond, F.; Arnaud, I. L.; Josserand, J.; Girault, H. H.; Rossier, J. S. Electrophoresis 2003, 24, 3-11.

(25) Arnaud, I.; Abid, J. P.; Roussel, C.; Girault, H. H. Chem. Commun. 2005, 6 , $787-788$.

(26) Fantini, S.; Clohessy, J.; Gorgy, K.; Fusalba, F.; Johans, C.; Kontturi, K.; Cunnane, V. J. Eur. J. Pharm. Sci. 2003, 18, 251-257. to other large ITIES, thus allowing the use of only two electrodes, adding to the simplicity of the setup. Another important issue is the use of small amounts of sample ( $5 \mu \mathrm{L}$ at most) due to the size of the interface and experimental setup.

The method is validated using simple tetraalkylammonium ions $\left(\mathrm{TBA}^{+}, \mathrm{TEA}^{+}, \mathrm{TMA}^{+}\right)$, which were already fully investigated by many authors, and can therefore be used as calibration for this new method. The present setup is then used to trace the ionic partition diagram of two lipophilic compounds: pyridine and 2,4dinitrophenol. The values of standard transfer potential, Gibbs energy of transfer, and partition coefficients are deduced from electrochemical studies performed with differential pulse voltammetry. Additionally, in the case of lipophilic acids and bases, not only the $\log (P)$ of the ionized species can be determined from the ionic partition diagram, but also the $\log (P)$ of the neutral species can be determined from the observed shift in $\mathrm{p} K_{\mathrm{a}}$.

\section{EXPERIMENTAL SECTION}

Chemicals. IPG gels (Immobiline DryPlates, linear $\mathrm{pH}$ range 4.0-7.0, 11-cm length and Immobiline Drystrips, linear $\mathrm{pH}$ range 3.0-10.0, 18-cm lentgh) were purchased from Amersham Biosciences. These IPG gels are received in a dried format and reswelled in aqueous solutions before use. In the gel, the $\mathrm{pH}$ gradient is built by acrylamide derivatives, called Immobilines, which are covalently fixed in the polyacrylamide gel. ${ }^{27}$ The general chemical formula of Immobilines is $\mathrm{CH}_{2}=\mathrm{CH}-\mathrm{CO}-\mathrm{NH}-\mathrm{R}$, where $\mathrm{R}$ is either a carboxylic acid or an amino group. Lithium chloride (>99\% purity), tetramethylammonium chloride, tetraethylammonium chloride, tetrabutylammonium chloride, NPOE, pyridine (PY), and 2,4-dinitrophenol (DNP) were purchased from Fluka and used as received. All aqueous solutions were prepared with deionized water from MilliQ System (Millipore) with $18.2 \mathrm{M} \Omega . \cdot \mathrm{cm}$ resistivity. The organic supporting electrolyte was prepared by metathesis of equimolar quantities of bis(triphenylphosphoranylidene) ammonium chloride and potassium tetrakis(4-chlorophenyl)borate (KT$\mathrm{PBCl}$ ) providing a BTPPATPBCl precipitate, which was filtered and recrystallized twice from acetone before use. BTPPATPBCl is very lipophilic and therefore gives a wide potential window.

Setup and Electrochemical Measurements. A two-electrode cell with a $\mathrm{Ag} / \mathrm{AgCl}$ working electrode in contact with the aqueous gel and a $\mathrm{Ag} / \mathrm{AgTPBCl}$ reference electrode in the organic phase were used. A piece of IPG gel of a given $\mathrm{pH}$ range was reswelled in a $100 \mathrm{mM} \mathrm{LiCl}$ aqueous solution. A $12-\mu \mathrm{m}$-polyethylene terephthalate (PET) film was coated with a layer of $\mathrm{Ag} / \mathrm{AgCl}$ (Ercon) screenprinting, and the resulting $\mathrm{PET} / \mathrm{Ag} / \mathrm{AgCl}$ electrode was dried for $2 \mathrm{~h}$ at $60^{\circ} \mathrm{C}$. In the PET/ $\mathrm{Ag} / \mathrm{AgCl}$ film, microholes of $\sim 50 \mu \mathrm{m}$ were drilled by photoablation (UV excimer laser, wavelength $193 \mathrm{~nm}$, energy $200 \mathrm{~mJ}$ ). The drilled PET/Ag/AgCl film electrode was then placed on the reswelled piece of gel with the silver/silver chloride side in contact with the gel, $\mathrm{Ag} / \mathrm{AgCl}$ thus acting as the working electrode for the aqueous gel. A droplet of organic phase was then used to cover the microhole and thus producing a micro-ITIES. A silver wire coated with silver tetrakis(4-chlorophenyl) borate $(\mathrm{Ag} / \mathrm{AgTPBCl})$, obtained by electrolysis of an $\mathrm{Ag}$ wire in a $\mathrm{KTPBCl}$ solution, was immersed in NPOE acting as the reference electrode for the organic phase. The correspond-

(27) Bjellqvist, B.; Ek, K.; Righetti, P. G.; Gianazza, E.; Gorg, A.; Westermeier, R.; Postel, W. J. Biochem. Biophys. Methods 1982, 6, 317-339. 


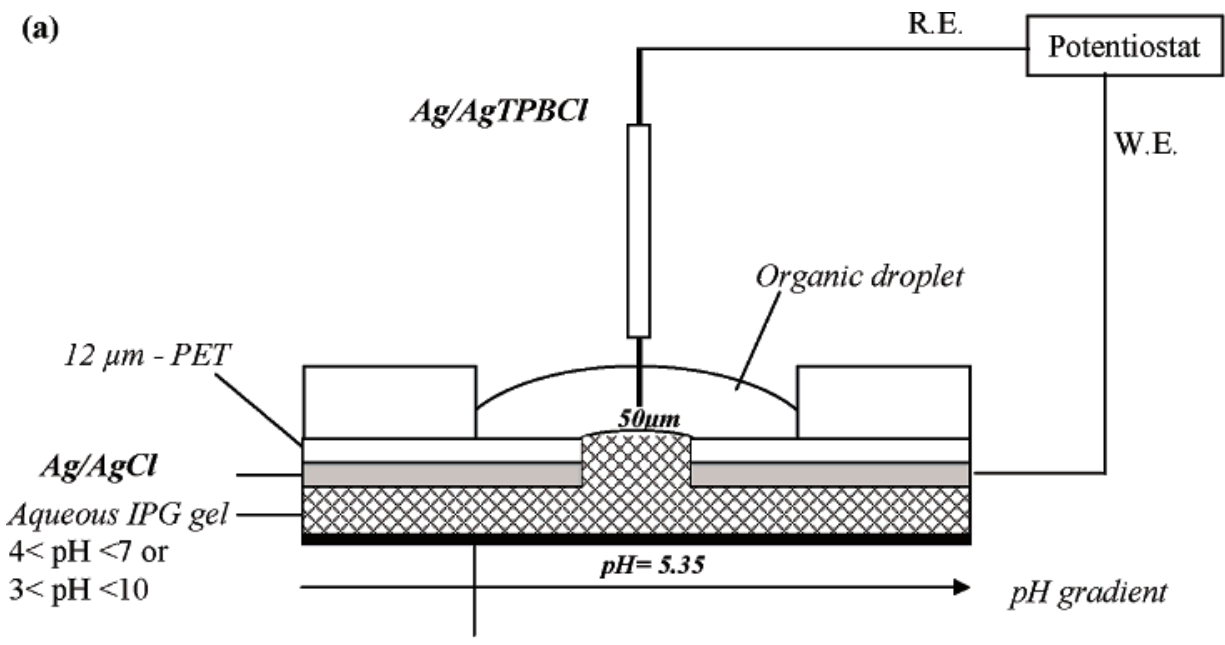

Gel PET substrate

(b)

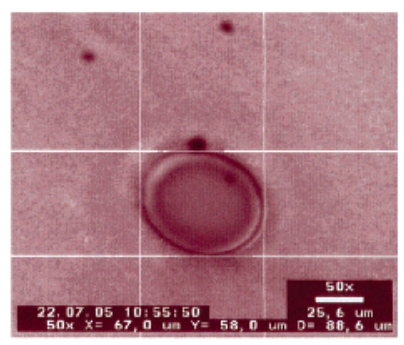

Top image $\phi=67 \mu \mathrm{m}$

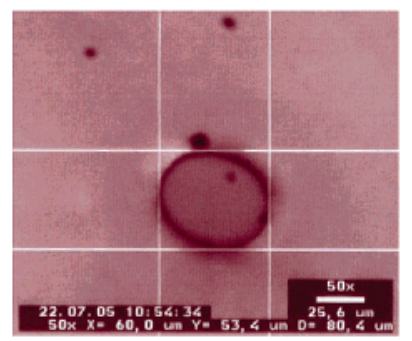

Bottom image $\phi=60 \mu \mathrm{m}$

(c)

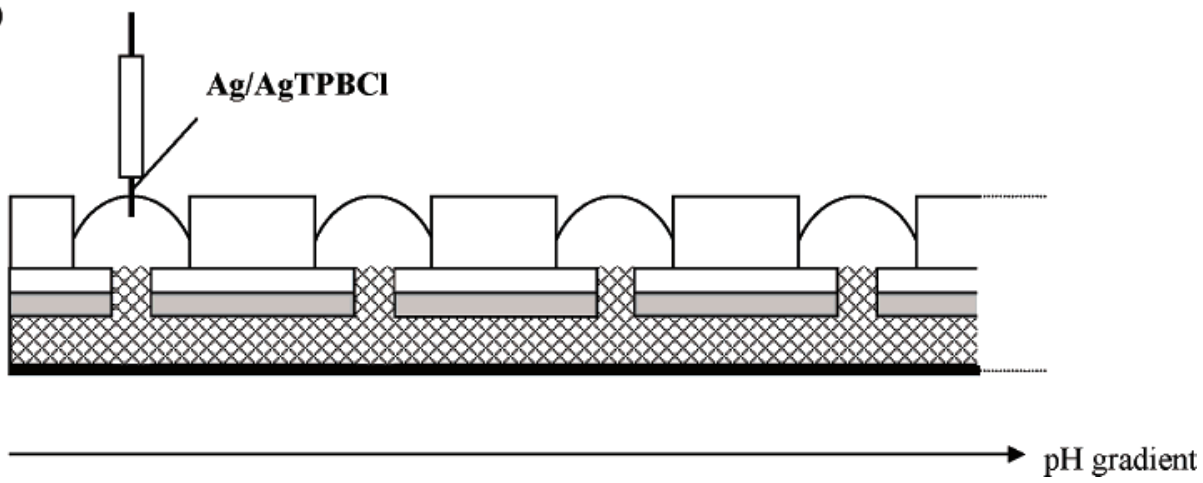

Figure 1. (a) Schematic presentation of the setup for the ITIES measurement at a single microhole at pH 5.35, (b) a microhole shape obtained after laser photoablation, seen under optical microscope, and (c) complete setup for lipophilicity measurements.

ing setup and the image of the film under the optical microscope are presented in Figure 1.

The advantage of the IPG gel in such a setup is that it offers a linear $\mathrm{pH}$ gradient, which allows us to scan overall the $\mathrm{pH}$ domain in one experiment and thus could lead to a highthroughput setup (Figure 1c) to measure partition coefficients. The linearity of the $\mathrm{pH}$ gradient has already been verified, ${ }^{28}$ and the geometric position of the microhole on the IPG gel strip thus determines, by linearity, the $\mathrm{pH}$ of the point where electrochemical measurements take place.

Electrochemical measurements were performed on an Autolab PGSTAT 12 with GPES version 4.9, Eco Chemie B.V. Differential pulse voltammetry (DPV) was used as electrochemical technique because for some of the drugs, traditional cyclic voltammograms display the peak close to the limit of the potential window, and

(28) DiMaïo, I. Ph.D. Thesis 3064, 2004; p 51. therefore, it is not an easy task to monitor the displacement of peak potential with $\mathrm{pH}$. The use of a differential pulse technique allows a better sensitivity, allowing the use of lower amounts of drugs for analysis. The presence of a peak instead of a wave also improves the discrimination of the transfer process from that of the base electrolytes. Furthermore, DPV also displays the experimental curves in a way that can be easily subtracted from the baseline, with a further increase in the discrimination against the base electrolytes.

Differential pulse voltammograms were registered after a 30-s equilibration at $-500 \mathrm{mV}$, followed by a scan from -400 to +500 $\mathrm{mV}$, with a modulation time of $60 \mathrm{~ms}$, an interval time of $400 \mathrm{~ms}$, a step potential of $2 \mathrm{mV}$, and a modulation amplitude of $50 \mathrm{mV}$.

Methodology: Use of an Internal Reference Ion. The applied potential difference, $E$, is theoretically defined as the potential applied between the two reference electrodes and is 
related to the Galvani potential difference $\Delta_{0}^{\mathrm{w}} \phi$ across the water/ NPOE interface by

$$
E=\Delta_{\mathrm{o}}^{\mathrm{w}} \phi+\Delta E_{\mathrm{ref}}
$$

where $\Delta E_{\text {ref }}$ depends on the reference electrodes, so that $E$ refers only to the electrochemical cell used. To calibrate the transfer potential, it is necessary to define a potential scale. The "TATB" assumption is most commonly used to define the standard Gibbs energy of transfer of an ion through an ITIES. ${ }^{29}$ Briefly, it states that the cation and anion of tetraphenylarsonium tetraphenylborate (TPAsTPB) have equal standard Gibbs energy of transfer for any pair of solvents, assuming that the solvation energies for both the cation and the anion are equal. On this basis, a scale for standard Gibbs energies of ion transfer and therefore for the standard transfer potential or the formal transfer potential can be obtained. For instance, the formal transfer potential of tetrabutylammonium $\left(\mathrm{TBA}^{+}\right)$at a water/NPOE interface can be estimated as - 241.5 $\mathrm{mV}^{22}$ In the following experiments, $\mathrm{TBA}^{+}$and tetramethylammonium $\left(\mathrm{TMA}^{+}\right)$will be used as internal reference ions to transpose the potentials measured to the potential scale on the basis of the "TATB" assumption, by the following relationship

$$
E_{\mathrm{i}}^{\mathrm{peak}}-\Delta_{\mathrm{o}}^{\mathrm{w}} \phi_{\mathrm{i}}^{0^{\prime}}=E_{\mathrm{TBA}^{+} \text {orTMA }}^{\mathrm{peak}}-\Delta_{\mathrm{o}}^{\mathrm{w}} \phi_{\mathrm{TBA}^{+} \mathrm{orTMA}^{+}}^{0^{\prime}}
$$

where $E_{\mathrm{i}}^{\text {peak }}$ is the peak potential measured by DPV for the transfer of compound $i$ and $\Delta_{\mathrm{o}}^{\mathrm{w}} \phi_{\mathrm{i}}^{0^{\prime}}$ is the formal standard transfer potential of compound i.

\section{RESULTS AND DISCUSSION}

Experimental Validation of the Electrochemical Cell Based on Transfer of Simple Permanent Ions. The following cell I is used to study the transfer of $\mathrm{TBA}^{+}$, tetraethylammonium $\left(\mathrm{TEA}^{+}\right.$), and $\mathrm{TMA}^{+}$across the aqueous gel/NPOE interface.

Cell I

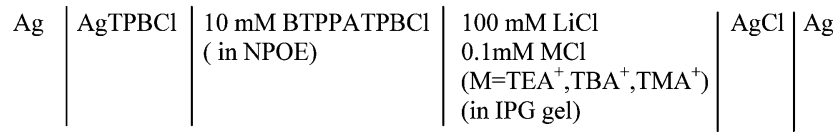

The Figure 2 dotted line shows the baseline measured by DPV when $\mathrm{LiCl}$ is in the aqueous gel $(\mathrm{pH} \mathrm{4.8)}$, defining the potential window of this electrochemical system. When the $\mathrm{pH}$ of the IPG gel is changed, there is no marked effect on the potential window for the differential pulse voltammograms (results not shown). This is also an indication that the acid-base buffer used in the IPG strip manufacturing does not introduce any transferable species into the electrochemical system. The positive side of the voltammogram (water versus organic phase) is limited by the transfer of $\mathrm{Li}^{+}\left(\Delta_{\mathrm{o}}^{\mathrm{w}} \phi_{\mathrm{Li}^{+}}^{0^{\prime}}=+576 \mathrm{mV}^{30}\right)$ and the negative side by the transfer of $\mathrm{Cl}^{-}\left(\Delta_{\mathrm{o}}^{\mathrm{w}} \phi_{\mathrm{Cl}^{-}}^{0^{\prime}}=-470 \mathrm{mV}^{31}\right)$. The range of potential window observed is $\sim 700 \mathrm{mV}$ and is similar to that obtained with a four-electrode setup or other three-electrode setups.

The solid line in Figure 2 shows the resulting DPV when all three ions were dissolved in the aqueous gel and their transfer

(29) Parker, A. J. Chem. Rev. 1969, 69, 1-32.

(30) Shao, Y. H.; Weber, S. G. J. Phys. Chem. 1996, 100, 14714-14720.

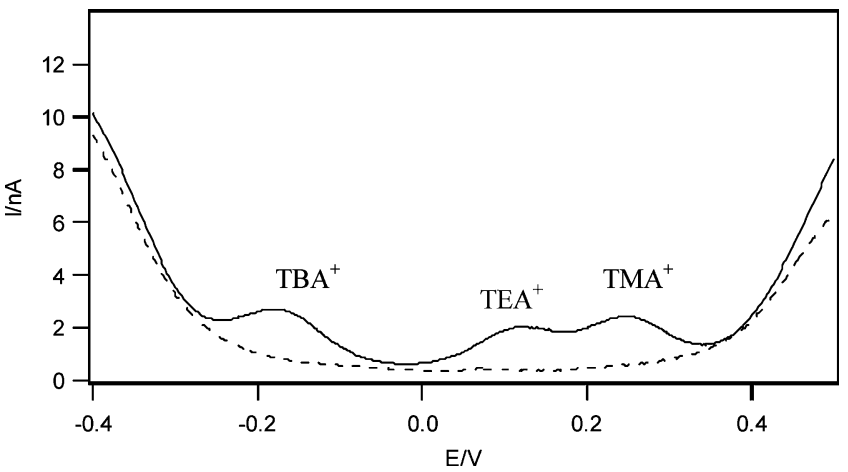

Figure 2. Transfer of $\mathrm{TBA}^{+}, \mathrm{TEA}^{+}$, and $\mathrm{TMA}^{+}$(solid line) and potential window (dotted line) seen by differential pulse voltammetry (modulation amplitude $50 \mathrm{mV}$, modulation time $60 \mathrm{~ms}$, interval time $400 \mathrm{~ms}$, step potential $2 \mathrm{mV}$ ).

Table 1. Thermodynamic Data Obtained for the Transfer of Simple lons at the NPOE/Water Interface

$\begin{array}{llll} & \mathrm{TBA}^{+} & \mathrm{TEA}^{+} & \mathrm{TMA}^{+} \\ \Delta_{\mathrm{o}}^{w} \phi^{0^{\prime}} / \mathrm{mV}^{a} & & 24.5 & 145.5 \\ \Delta G_{t r}^{0, \mathrm{w} \rightarrow \mathrm{o}} / \mathrm{kJ} \cdot \mathrm{mol}^{-1 a} & & 2.4 & 14.0 \\ \Delta_{\mathrm{o}}^{w} \phi^{0^{\prime}} / \mathrm{mV}^{b} & -241.5 & 27 & 111 \\ \Delta G_{t r}^{0, \mathrm{w} \rightarrow \mathrm{o}} / \mathrm{kJ}^{\circ} \cdot \mathrm{mol}^{-1 b} & -23.3 & 2.6 & 10.7 \\ \Delta_{\mathrm{o}}^{w} \phi^{0^{\prime}} / \mathrm{mV}^{c} & & 26 & 140 \\ \Delta G_{t r}^{0, \mathrm{w} \rightarrow \mathrm{o}} / \mathrm{kJ}^{c} \cdot \mathrm{mol}^{-1 c} & & 2.5 & 13.5\end{array}$

${ }^{a}$ According to this work. ${ }^{b}$ According to Samec et al. ${ }^{22}{ }^{c}$ According to Wilke et al. ${ }^{18}$

across the gel/NPOE interface takes place. A higher potential is needed to transfer $\mathrm{TEA}^{+}$from the aqueous to the organic phase than to transfer $\mathrm{TBA}^{+}$. $\mathrm{TBA}^{+}$is thus a less hydrophilic ion than $\mathrm{TEA}^{+}$, which is less hydrophilic than $\mathrm{TMA}^{+}$.

Based on the TATB assumption (see Methodology: Use of an Internal Reference Ion), the standard transfer potentials of $\mathrm{TEA}^{+}$and $\mathrm{TMA}^{+}$can be determined, if taking $\mathrm{TBA}^{+}$as internal reference. The value of the standard transfer potential of $\mathrm{TBA}^{+}$ was determined by Samec et $\mathrm{al} .{ }^{22}$ to be $-241.5 \mathrm{mV}$. The relative transfer potentials measured by DPV for $\mathrm{TBA}^{+}, \mathrm{TEA}^{+}$, and $\mathrm{TMA}^{+}$ are $E_{\mathrm{TBA}^{+}}^{\text {peak }}=-157 \mathrm{mV}, \mathrm{E}_{\mathrm{TEA}^{+}}^{\text {peak }}=109 \mathrm{mV}$, and $\mathrm{E}_{\mathrm{TMA}^{+}}^{\text {peak }}=230 \mathrm{mV}$, respectively. The standard transfer potentials of $\mathrm{TEA}^{+}$and $\mathrm{TMA}^{+}$ can be calculated by eq 2 as 24.5 and $145.5 \mathrm{mV}$, respectively, values that are quite close to the values reported in the literature (see Table 1).

The results show that the present two-electrode electrochemical cell is validated and can be used, in an easy and fast way, to measure the standard transfer potential for simple permanent ions. It also indicates that, for simple and permanent ions, the hydration in the aqueous gel medium is similar to that in free aqueous solution and that for these ions the interface between aqueous gel and NPOE behaves like a water/NPOE interface.

Ionic Partition Diagram of Ionizable Compounds. Ionic partition diagrams were first developed by Reymond et al. ${ }^{8}$ as a representation of the predominance area of the various species of an ionizable compound as a function of the Galvani potential difference and the $\mathrm{pH}$ and taking into account the thermodynamic

(31) Shao, Y.; Stewart, A. A.; Girault, H. H. J. Chem. Soc., Faraday Trans. 1991, $87,2593-2597$. 
equilibrium governing the distribution of various acid/base forms of molecules involved. Two adjacent areas of predominance are separated by equiconcentration boundary lines. These diagrams have shown to be a useful tool to predict and interpret the transfer mechanisms of ionizable drugs at the ITIES, and their concept is similar to the potential- $\mathrm{pH}$ diagrams of metals (Pourbaix diagrams). Initial studies were dedicated to drawing ionic partition diagrams for hydrophilic ionizable compounds, but more recent studies by Gobry et $a .^{13}$ have extended this partition diagram model to lipophilic species. For lipophilic molecules, the concentration of the neutral form in the aqueous phase is negligible compared to that in the organic phase, and ionic partition diagrams displaying the neutral species in water, as was the case for hydrophilic diagrams, are less relevant in the case of lipophilic molecules. The new model for lipophilic compounds takes into account the neutral species in the organic phase when deriving the equations defining the boundary lines.

As shown previously, ${ }^{13}$ for a lipophilic monobase B partitioned between two immiscible phases, the ionic partition diagram is determined by three boundary lines (equiconcentration convention):

$$
\text { line 1: } \quad \Delta_{\mathrm{o}}^{\mathrm{w}} \phi=\Delta_{\mathrm{o}}^{\mathrm{w}} \phi_{\mathrm{BH}^{+}}^{0^{\prime}}
$$

line 2: $\quad \mathrm{pH}=\mathrm{p} K_{\mathrm{a}}-\log P_{\mathrm{B}}^{0}$

line 3: $\Delta_{\mathrm{o}}^{\mathrm{w}} \phi=\Delta_{\mathrm{o}}^{\mathrm{w}} \phi_{\mathrm{BH}^{+}}^{0^{\prime}}+\frac{2,3 R T}{F}\left(\log P_{\mathrm{B}}^{0}-\mathrm{p} K_{\mathrm{a}}\right)+\frac{2,3 R T}{F} \mathrm{pH}$

For a lipophilic monoacid AH partition between two immiscible phases, the ionic partition diagram is determined by the following boundary lines (equiconcentration convention): $:^{13}$

$$
\begin{gathered}
\text { line } 1: \quad \Delta_{\mathrm{o}}^{\mathrm{w}} \phi=\Delta_{\mathrm{o}}^{\mathrm{w}} \phi_{\mathrm{A}^{-}}^{0^{\prime}} \\
\text { line 2: } \mathrm{pH}=\mathrm{p} K_{\mathrm{a}}+\log P_{\mathrm{AH}}^{0} \\
\text { line 3: } \Delta_{\mathrm{o}}^{\mathrm{w}} \phi=\Delta_{\mathrm{o}}^{\mathrm{w}} \phi_{\mathrm{A}^{-}}^{0^{\prime}}-\frac{2,3 R T}{F}\left(\log P_{\mathrm{AH}}^{0}+\mathrm{p} K_{\mathrm{a}}\right)+\frac{2,3 R T}{F} \mathrm{pH}
\end{gathered}
$$

As an illustration of the methodology using the two-electrode gel cell described above, a monobase, pyridine, and a monoacid, 2,4dinitrophenol, were investigated by DPV. Cell II is used to study the transfer of the two drugs across the IPG gel/NPOE interface at different $\mathrm{pH}$ values, to evaluate their standard transfer potentials and partition coefficients and draw their ionic partition diagrams.

Cell II

$$
\begin{array}{l|l|l|l|l|l}
\mathrm{Ag} & \mathrm{AgTPBCl} & \begin{array}{l}
10 \mathrm{mM} \text { BTPPATPBCl } \\
\text { (in NPOE) } \\
0.6 \mathrm{mM} \mathrm{PY} \\
\text { or } 1.13 \mathrm{mM} \text { DNP }
\end{array} & \begin{array}{l}
100 \mathrm{mM} \mathrm{LiCl} \\
1 \mathrm{mM} \mathrm{MCl} \\
\text { (in IPG gel) }
\end{array} & \mathrm{AgCl} & \mathrm{Ag}
\end{array}
$$

and $\mathrm{M}^{+}=\mathrm{TBA}^{+}$for PY and $\mathrm{TMA}^{+}$for DNP.

In each case, small amounts of drugs were added to the organic phase; the volume of the droplet of organic phase needed was 3 $\mu \mathrm{L}$. $\mathrm{TBA}^{+}$was added to the gel phase to work as internal reference when pyridine was studied and $\mathrm{TMA}^{+}$when 2,4-dinitrophenol was studied.

Figure 3 shows the evolution of the voltammograms obtained by $\mathrm{DPV}$ for pyridine at different $\mathrm{pH}$. For $\mathrm{pH}$ values below the $\mathrm{p} K_{\mathrm{a}}$,

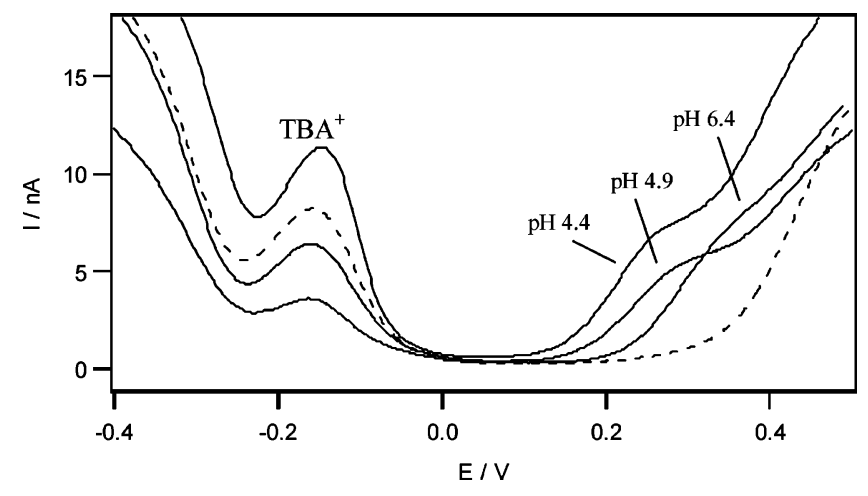

Figure 3. Differential pulse voltammograms representing the transfer for pyridine at the IPG gel/NPOE interface at $\mathrm{pH} 4.4,4.9$, and 6.4 (solid lines). All the voltammograms are referenced against $\mathrm{TBA}^{+}$, which was added to the gel phase in the electrochemical cell. The dotted line is the baseline measured in the presence of $\mathrm{TBA}^{+}$ only. (DPV parameters: modulation amplitude $50 \mathrm{mV}$, modulation time $60 \mathrm{~ms}$, interval time $400 \mathrm{~ms}$, step potential $2 \mathrm{mV}$.)

the standard transfer potential remains independent of the $\mathrm{pH}$ (within experimental error) and represents the transfer of protonated pyridine $\left(\mathrm{PyH}^{+}\right)$. The peak current decreases as the $\mathrm{pH}$ approaches the $\mathrm{p} K_{\mathrm{a}}$, following the decrease in the concentration of $\mathrm{PyH}^{+}$. When the $\mathrm{pH}$ is higher than the $\mathrm{p} K_{\mathrm{a}}$, the standard transfer potential shifts toward higher values as can be observed in Figure 3. The peak current is the result of the transfer of a proton facilitated by the neutral pyridine present in the organic phase, and which behaves as an ionophore for the proton. The transfer is limited by the proton concentration, which explains the shift of potential toward higher values (in theory the potential shifts by $2,3 R T / z F \mathrm{mV}$ per $\mathrm{pH}$ unit. Here, one proton is transferred; thus the slope is $59 \mathrm{mV} / \mathrm{pH}$ unit). In this case, the mechanism can be described as a transfer by interfacial complexation (TIC). ${ }^{32}$ In addition, Figure 3 shows that it becomes more difficult to monitor the transfer peak at higher $\mathrm{pH}$, as it is shifting toward the limit of the potential window. This case proves the relevance of using DPV as the electrochemical technique, as it allows us to subtract the baseline from the voltammogram measured, thus allowing a better peak discrimination against the base electrolytes.

As shown in Figure 4, the experimental results obtained using DPV at different aqueous $\mathrm{pHs}$ can be used to draw the ionic partition diagrams for pyridine (a) and for 2,4-dinitrophenol (b). For 2,4-dinitrophenol, the processes describing the transfer are similar to the ones described above. For $\mathrm{pH}$ values below the $\mathrm{p} K_{\mathrm{a}}, 2,4$ dinitrophenol is in its neutral form (DnpH). Present in the organic phase, it behaves as an ionophore for proton, the assisted proton transfer is thus described as a transfer by interfacial dissociation; ${ }^{32}$ the potential shifts by $59 \mathrm{mV} / \mathrm{pH}$ unit. For $\mathrm{pH}$ values higher than the $\mathrm{p} K_{\mathrm{a}}$, the transfer of the deprotonated drug $\left(\mathrm{Dnp}^{-}\right)$is observed and the transfer potential remains independent of the $\mathrm{pH}$.

For the monobase pyridine, the diagram in Figure 4a shows that, for $\mathrm{pH}$ values below the $\mathrm{p} K_{\mathrm{a}}$, the transfer potential measured for the protonated drug remains constant. We can thus obtain the values of the standard transfer potential, the Gibbs energy of

(32) Shao, Y.; Osborne, M. D.; Girault, H. H. J. Electroanal. Chem. 1991, 318, 101-109. 

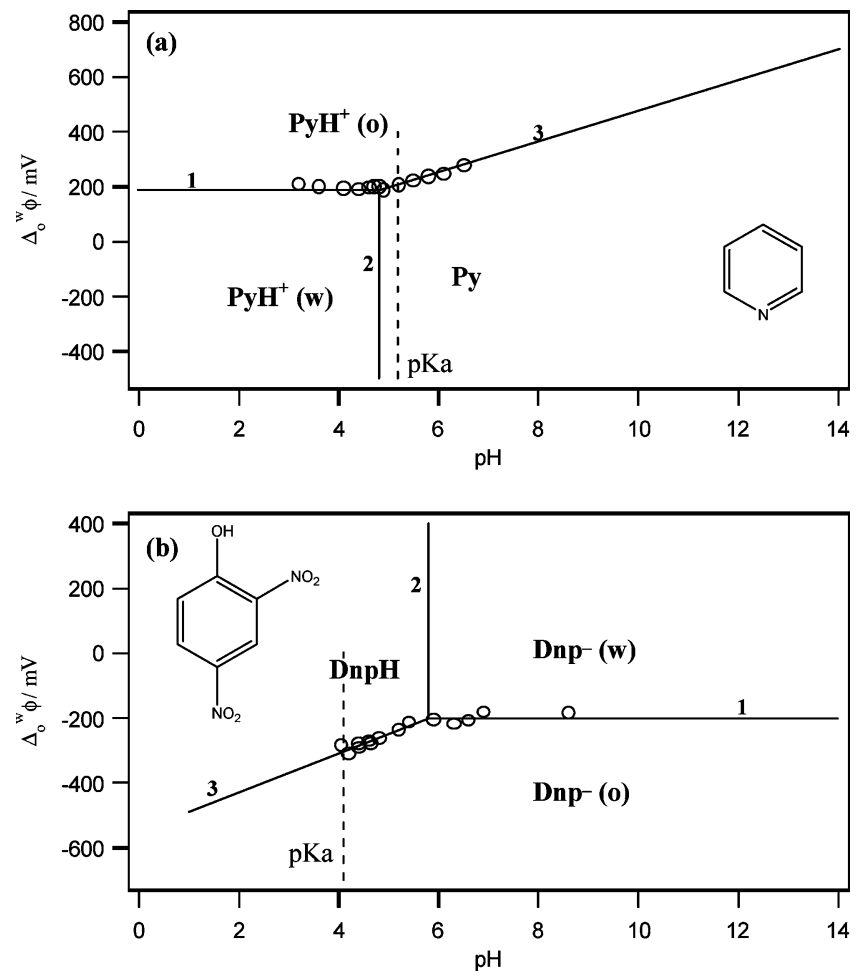

Figure 4. Ionic partition diagrams of (a) $P Y(0.6 \mathrm{mM})$ and (b) DNP $(1.13 \mathrm{mM})$ at the IPG gel/NPOE interface. The dotted lines show the aqueous $\mathrm{p} K_{\mathrm{a}}$ value of each compound under study. Equations for lines $1-3$ are displayed in the text.

transfer, and the standard partition coefficient of the ionized forms from the DPV and eqs 3 and 4.

$$
\begin{aligned}
\Delta_{\mathrm{o}}^{\mathrm{w}} \phi^{0^{\prime}} & =\frac{\Delta G_{t r}^{0, \mathrm{w} \rightarrow \mathrm{o}}}{z F} \\
\log P^{0} & =-\frac{\Delta G_{t r}^{0, \mathrm{w} \rightarrow 0}}{2.3 R T}
\end{aligned}
$$

For the monoacid 2,4-dinitrophenol (Figure 4b), the values of the standard Gibbs energy of transfer and standard partition coefficient of the ionized form can be obtained for $\mathrm{pH}$ values higher than the $\mathrm{p} K_{\mathrm{a}}$ and from the DPV and eqs 3 and 4 as well. The thermodynamic data obtained for the two drugs are summarized in Table 2 and are comparable to literature values.

Both diagrams shown in Figure 4 illustrate the shift in $\mathrm{p} K_{\mathrm{a}}$ for the vertical line (dotted lines), as predicted for lipophilic compounds. The effective $\mathrm{p} K_{\mathrm{a}}$ measured give access to the partition coefficient of the neutral species. For 2,4-dinitrophenol, knowing the aqueous acidic constant $\left(\mathrm{p} K_{\mathrm{a}}=4.10\right)$, and measuring an effective $\mathrm{p} K_{\mathrm{a}}$ of 5.8 , the above theory predicts a value of 1.7 for $\log P_{\mathrm{AH}}$ of the neutral compound, which is quite close to values measured by Ulmeanu et al. ${ }^{14}$ using cyclic voltammetry and potentiometry. For pyridine, the $\log P_{\mathrm{B}}$ of the neutral compound is estimated to be 0.3 , which is comparable to the value measured by Liu et al. ${ }^{5}$ using potentiometry and the shake flask method. As summarized in Table 2, standard transfer potential values and standard partition coefficients for neutral as well as ionized species can be easily and rapidly deduced from our voltammetric measurements. One problem encountered when performing the
Table 2. Thermodynamic Data Obtained for the Transfer of Ionizable Compounds at the NPOE/Water Interface

$\begin{array}{lcc} & \text { pyridine } & \text { 2,4-dinitrophenol } \\ & 5.16^{a} & 4.1^{b} \\ \mathrm{p} K_{\mathrm{a}} & 190^{d} & -200^{d} \\ \Delta_{\mathrm{o}}^{w} \phi^{0^{\prime}} / \mathrm{mV} \text { (in NPOE) } & 18.3^{d} & -18.4^{d} \\ \Delta G_{t r}^{0, \mathrm{w} \rightarrow \mathrm{NPOE}} / \mathrm{kJ} \cdot \mathrm{mol}^{-1} & -3.2^{d} & -3.4^{d} \\ \log P_{\mathrm{NPOE}}^{0} \text { (ionized) } & & -2.23^{b} \\ & 0.3^{d} & 1.7^{d} \\ \log P_{\mathrm{NPOE}} \text { (neutral) } & 0.26^{c} & 2.0^{b}\end{array}$

${ }^{a}$ According to Reymond et al. ${ }^{2}{ }^{b}$ According to Ulmeanu et al. ${ }^{14}$ ${ }^{c}$ According to Liu et al. ${ }^{d}{ }^{d}$ According to this work.

measurements was that the reswelled gel would dry faster under higher temperatures, thus disturbing the reproducibility of the measurements and slightly shifting the potential window compared to the baseline. Thus, measurements had to be done in a short time, to avoid the gel drying too much. The conception of a new and closed setup, where water is constantly provided to reswell the gel, would be a solution to this problem.

\section{CONCLUSIONS}

The electrochemical behavior of two ionizable drugs has been investigated with a two-electrode gel cell. This setup offers a fast and easy way to measure standard transfer potential for simple permanent ions as well as for ionizable drug compounds; as preparation of the electrochemical cell is simple, there is no need to adjust the $\mathrm{pH}$ of aqueous phase as it is determined by a commercial IPG gel. In addition, results obtained with this twoelectrode setup are comparable to those obtained with classical $\mathrm{L} / \mathrm{L}$ systems and it is relevant to notice that only small amounts of organic phase, hence of drugs, were needed. The values of the standard transfer potential, the Gibbs energy of transfer, and the partition coefficients for the ionized and neutral forms of these drugs are evaluated by differential pulse voltammetry. This technique has proven to be superior to cyclic voltammetry for monitoring ion transfer, especially when the peak is close to the limit of the potential window, as is often the case for extreme $\mathrm{pH}$ values. The experimental results are presented in the form of ionic partition diagrams that allow us to predict which form of an ionizable solute will transfer across the $\mathrm{L} / \mathrm{L}$ interface under given conditions of potential and $\mathrm{pH}$. From the $\mathrm{pH}-$ potential diagram, it is possible to evaluate the $\log (P)$ of the neutral species from the shift of $\mathrm{p} K_{\mathrm{a}}$ observed. Studies on drug-transfer mechanisms are of great significance for the understanding of $\mathrm{L} / \mathrm{L}$ interfaces and drug disposition.

\section{ACKNOWLEDGMENT}

The authors acknowledge the Swiss National Science Foundation for financial support. C.M.P. thanks FCT for the contract SFRH/BSAB/502/2005.

Received for review October 10, 2005. Accepted December 15, 2005.

AC051808A 